\title{
ZEOLITE DEVELOPMENT FROM FLY ASH AND UTILIZATION IN LIGNITE MINE-WATER TREATMENT
}

\author{
G. Itskos ${ }^{1 *}$, A. Koutsianos², N. Koukouzas ${ }^{2}$, C. Vasilatos ${ }^{3}$ \\ 1) Nazarbayev University, School of Engineering, Astana, Kazakhstan; *grigorios.itskos@nu.edu.kz; 2) Centre for Research and \\ Technology Hellas/Chemical Process and Energy Resources Institute; 4) ${ }^{\text {th }} \mathrm{km}$ Ptolemais-Mpodosakeion N.R., Ptolemais 50200), \\ Greece; 3) National \& Kapodistrian University of Athens, Department of Geology \& Geoenvironment, Panepistimioupolis, Ano \\ Ilissia 157) 84, Athens, Greece.
}

Materials and methods. Fly ash from two lignite-fed power stations of Greece has been utilized as raw material to synthesize zeolitic materials with upgraded adsorption capacity. Two different siliceous fly ash samples (barely Class C -AS TM C618) underwent hydrothermal treatment at fixed solid / liquid ratio $(50 \mathrm{~g} \mathrm{FA} / 1 \mathrm{~L} \mathrm{NaOH})$ and constant temperature $\left(90^{\circ} \mathrm{C}\right)$. The zeolitic products have been characterized for their microstructure, chemical, and mineralogical composition by means of SEM, FAAS, and XRD, respectively. In light of their prospective utilization as liquid-phase sorbents, the specific surface area \& porosity of samples were also determined by means of $\mathrm{N}_{2}$-porosimetry.

Results and discussion. Various types of Na-zeolites have been identified as the predominant phases in the synthetic materials. Selected zeolitic samples were tested for their actual heavy metal-removal capacity by water sampled from lignite mines in Northern Greece. Artificial aquatic samples with known concentration of heavy metals were also used, showing that the synthetic zeolitic materials are able to uptake a wide variety of potential pollutants with up to $100 \%$ efficiency.

Conclusions. The synthetic zeolitic materials were tested comparatively, showing that the more intense the zeolitic presence in the synthetic materials, the greater the uptake rates for certain groups of trace elements. 